\section{Making Colony PCR Easier by Adding Gel- Loading Buffer to the Amplification Reaction}

BioTechniques 28:424-426 (March 2000)

Because of its simplicity, PCR performed directly from bacterial colonies on agar plates has been extensively used as a first step in the identification of recombinant clones $(1-3,6,7)$. Instead of making DNA minipreps and restriction digestion from several putative recombinant colonies, colony PCR allows the identification of the positive clones, and so reduces these procedures to one clone per ligation experiment.

When several ligations are being performed simultaneously or when the recombinant frequency is expected to be low and no blue/white screening is available, it is necessary to perform several colony PCR amplifications. We realized that colony PCR could be made easier if the gel-loading buffer was included in the amplification mix instead of being added individually to each tube just before the electrophoresis. We evaluated the effects of three widely used gel-loading buffers on the amplification of targets with different sizes, from different sources and using several primer combinations.

Plasmids containing inserts with different sizes and coming from different sources were introduced into $E s$ cherichia coli strain DH5 $\alpha^{\mathrm{TM}}$ (Life Technologies, Gaithersburg, MD, USA) by a calcium chloride method (5). Bacterial lysate was obtained from ampicillin-resistant colonies on LB plates by a slight modification of Güssow and Clackson (2): colonies (0.5-1.5 mm diameter) were picked and transferred to $50 \mu \mathrm{L}$ water, boiled for $5 \mathrm{~min}$ and stored at $4^{\circ} \mathrm{C}$ until used. Gel-loading buffers (5) were prepared as $6 \times$ concentrated stocks: for buffer I, $0.25 \%(\mathrm{wt} / \mathrm{vol})$ bromophenol blue, $0.025 \%(\mathrm{wt} / \mathrm{vol})$ xylene cyanol FF and $40 \%$ (wt/vol) sucrose in water; for buffer II, $0.25 \%$ (wt/vol) bromophenol blue, $0.025 \%$ (wt/vol) xylene cyanol FF and $15 \%$ (wt/vol) Ficoll (Type 400) in water and for buffer III, $0.25 \%$ (wt/vol) bromophenol blue, $0.025 \%$ (wt/vol) xylene cyanol $\mathrm{FF}$ and $30 \%$ (vol/vol) glycerol in water. PCR amplifications were carried out by mixing $2 \mu \mathrm{L}$ lysate with $8 \mu \mathrm{L}$ of a premixture so that the final concentration of each reaction was $50 \mathrm{mM} \mathrm{KCl}, 1.5 \mathrm{mM} \mathrm{MgCl} 2,10 \mathrm{mM}$ Tris-HCl, pH 9.0, $200 \mu \mathrm{M}$ each dNTP, $0.4 \mu \mathrm{M}$ of each primer, $0.5 \mathrm{U}$ of $\mathrm{Taq}$ DNA polymerase (Amersham Pharmacia Biotech, São Paulo, Brazil) and gelloading buffer to final concentrations of $0,0.25$ and $0.5 \times$, respectively. (These low concentrations still cause DNA samples to sink into the gel wells.) The inserts were amplified in $0.2 \mathrm{~mL}$ tubes for 30 cycles at $94^{\circ} \mathrm{C}$ for $30 \mathrm{~s}, 55^{\circ} \mathrm{C}$ for $30 \mathrm{~s}$ and $72^{\circ} \mathrm{C}$ for $2 \mathrm{~min}$, followed by a 7 min final extension at $72^{\circ} \mathrm{C}$ using a GeneAmp ${ }^{\circledR}$ PCR System 9700 thermal cycler (PE Biosystems, Foster City, CA, USA). The reactions were separated by electrophoresis on a $1 \%$ TAE agarose gel.

To evaluate the effects of the three gel-loading buffers on target amplification efficiency, six reactions were per-

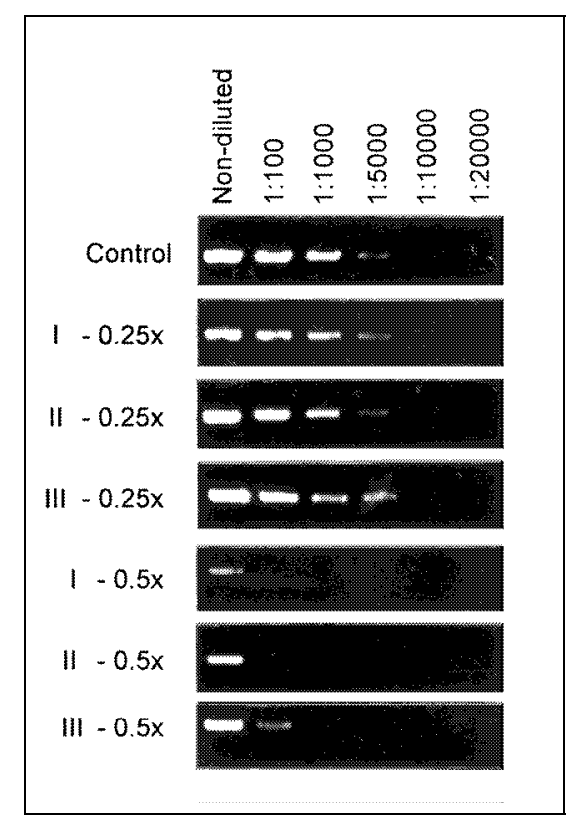

Figure 1. Colony PCR from bacterial lysate dilutions using electrophoresis loading buffers in the amplification reaction. PCR amplification was performed without loading buffer (control) or using $0.25 \times$ or $0.5 \times$ final concentration of buffers I, II and III as indicated on the left. The lysate dilutions used in the PCR are indicated over each lane. PCR amplifications were done using forward (5'-GTAAAACGACGGCCAGT-3') and reverse (5'-AACAGCTATGACCATGATTAC-3') primers (MWG-Biotech, Ebersberg, Germany). Reactions were separated on a $1 \%$ agarose gel. formed in parallel, using $2 \mu \mathrm{L}$ of nondiluted lysate and lysate dilutions of $1: 100,1: 1000,1: 5000,1: 10000$ and 1:20000 with water. The DNA construct used, pA14, contains a $359 \mathrm{bp}$ insert corresponding to the $3^{\prime}$ untranslated region from an aluminum-induced maize gene (our unpublished results) cloned in pGEM $^{\circledR}-\mathrm{T}$ Easy (Promega, Madison, WI, USA). Figure 1 shows that colony PCR performed without gel-loading buffers allowed abundant target amplification even when the bacterial lysate was diluted to $1: 1000$. The overall amplification in the presence of $0.25 \times$ of buffers I, II or III was similar to the control reaction (no loading buffer in the PCR mixture). At a 5000-fold dilution, a faint band was still observed in both the control and in the samples containing any of the gel-loading buffers.

With a $0.5 \times$ final concentration of any of the three buffers, the target was still amplified in those samples starting from non-diluted bacterial lysate. However, in the samples amplified with buffer I, the decrease in the amplification efficiency was higher. The effect of the $0.5 \times$ buffer concentration was clearly seen in the samples amplified from the lysate dilutions because at a 100 -fold dilution, a faint band could be observed only with buffer III. At higher dilutions, no amplification could be detected with any of the three gel-loading buffers.

To verify the performance of the loading buffers on the amplification of larger inserts, a PCR was performed using the lysate obtained from colonies transformed with p715 (4). This construct contains a $3046 \mathrm{bp}$ insert that corresponds to the maize $H R G P$ promoter fused to the GUS coding region

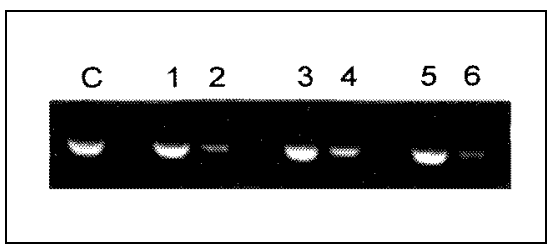

Figure 2. Amplification of a 3046 bp insert by colony PCR using three different loading buffers. Insert amplification was performed as described in Figure 1, using undiluted bacterial lysate. Reactions were separated on a $1 \%$ agarose gel. C: control (no loading buffer), 1: $0.25 \times$ buffer I; 2 : $0.5 \times$ buffer I; $3: 0.25 \times$ buffer II; $4: 0.5 \times$ buffer II; 5: $0.25 \times$ buffer III and $6: 0.5 \times$ buffer III. 
from $E$. coli and the $3^{\prime}$ terminator region from Agrobacterium tumefaciens cloned in pBluescript ${ }^{\circledR}$ KS II (Stratagene, La Jolla, CA, USA). All loading buffers allowed the target amplification at 0.25 and $0.5 \times$ final concentration (Figure 2). However, at $0.5 \times$ final concentration, there was a decrease in the amplification that was more pronounced than that observed with the $359 \mathrm{bp}$ target depicted in Figure 1.

After the $0.25 \times$ gel-loading buffers in the PCR mixture proved to be feasible even when the bacterial lysate was diluted 1000-fold, we simplified our protocol: we added the bacterial colony directly to the $10 \mu \mathrm{L}$ of the PCR mixture distributed in the $0.2 \mathrm{~mL}$ tubes, according to Lee and Cooper (3). The cycling parameters were the same as already described except for the inclusion of one step at $94^{\circ} \mathrm{C}$ for $3 \mathrm{~min}$ before carrying out the 30 cycles. This protocol was used to amplify targets with intermediate sizes and to use other primers, as seen in Figure 3, using

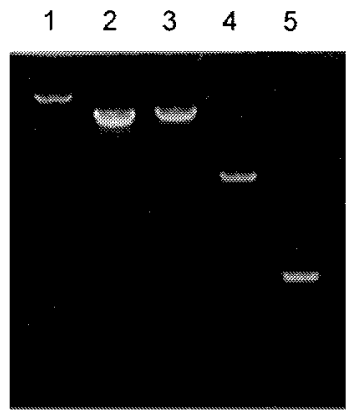

Figure 3. Colony PCR from plasmids containing inserts differing in size, source and using different primers. Amplifications were done directly from bacterial colonies coming from plasmids containing: lane 1, a 5046 bp insert corresponding to the pET3d entire sequence (New England Biolabs, Hitchin, England, UK) plus part of the coding region from the maize Zmall gene $\left(G e n B a n k{ }^{\circledR}\right.$ Accession No. AF031083) using two gene-specific primers. Lane 2, a 3046 bp insert from p715 amplified with forward and reverse primers; lane 3 , the same as in lane 2, using T3 (5'-AATTAACCCTCACTAAAGGG-3') and T7 (5'-TACGACTCACTATAGGGCGA-3') primers. Lane 4, a 2124 bp insert containing a plant virus promoter, the coding region from a Panicum miliaceum gene and the $3^{\prime}$ terminator from Agrobacterium tumefaciens, using forward and reverse primers. Lane 5, a 662 bp insert corresponding to a part of a plant virus promoter and the coding region of Zmall gene amplified with gene-specific primers.
$0.25 \times$ buffer I (buffers II and III worked as well; results are not shown). Using Taq DNA polymerases from other brands or a PCR apparatus requiring mineral oil on the top of the reaction mixture was also successful (results not shown).

In conclusion, our results showed that the three gel-loading buffers can be added to the PCR mixture used to amplify target inserts from bacterial colonies, decreasing considerably the tedious handling of several small 0.2 $\mathrm{mL}$ tubes that are currently used in the most recent thermocyclers. We found that a $0.25 \times$ concentration of any of the three gel-loading buffers does not decrease target amplification, although a negative effect was observed at a $0.5 \times$ concentration. Finally, by decreasing the reaction volume to $10 \mu \mathrm{L}$, the cost of the assay is considerably lower.

\section{REFERENCES}

1.Dallas-Yang, Q., G. Jiang and F.M. Sladek. 1998. Avoiding false positives in colony PCR. BioTechniques 24:580-582.

2.Güssow, D. and T. Clackson. 1989. Direct clone characterization from plaques and colonies by the polymerase chain reaction. Nucleic Acids Res. 17:4000.

3.Lee, A.B. and T.A. Cooper. 1995. Improved direct PCR screen for bacterial colonies: wooden toothpicks inhibit PCR amplification. BioTechniques 18:225-226.

4.Menossi, M., J.A. Martínez-Izquierdo and P. Puigdomènech. 1997. Tissue specific activity and hormone control of the promoter of the gene coding for a maize hydroxyprolinerich glycoprotein. Plant Sci. 125:189-200.

5.Sambrook, J., E.F. Fritsch and T. Maniatis. 1989. Molecular Cloning: A Laboratory Manual. CSH Laboratory Press, Cold Spring Harbor, NY.

6.Sandhu, G.S., J.W. Precup and B.C. Kline. 1989. Rapid one-step characterization of recombinant vectors by direct analysis of transformed Escherichia coli colonies. BioTechniques 7:689-690.

7.Zon, L.I., D.M. Dorfman and S.H. Orkin. 1989. The polymerase chain reaction colony miniprep. BioTechniques 7:696-698.

We thank Dr. M.J. da Silva for his help with the manuscript and D. Johnson for revising the manuscript. The research in our laboratory was supported by Grants from PADCT/CNPq (62.0472/98-7) to M.M. and from the European Community (ERBIC19CT-960089) and FAPESP (94/033581-1) to P.A. M.M., L.G.M. and N.C.J. are recipients fellowships from FAPESP, Brazil. Address correspondence to Marcelo Menossi, Centro de Biologia Molecular e Engenharia Genética, C.P. 6109, Universidade Estadual de Campinas, CEP 13083-970. Campinas, SP, Brazil. Internet: menossi@unicamp.br

Received 11 June 1999; accepted 19 November 1999.

\section{Marcelo Menossi, Nilson Cremonese, Jr., Lyza G. Maron and Paulo Arruda Universidade Estadual de Campinas Campinas, Brazil}

\section{Heating Greatly Speeds Coomassie Blue Staining and Destaining}

BioTechniques 28:426-432 (March 2000)

SDS-PAGE is one of the most powerful and commonly used techniques in molecular biology. The most frequently used dye for visualizing proteins is Coomassie Brilliant Blue R-250 because of its relatively high sensitivity $(3,6)$. However, its lengthy processing time is a major drawback of the standard Coomassie staining technique. Sambrook et al. (4) state that a staining time of at least $4 \mathrm{~h}$ is needed, with destaining overnight. This can be shortened to a minimum of $1 \mathrm{~h}$ staining time, but at least several hours of destaining are needed to start to visualize bands. In addition, the destaining process is often incomplete even after overnight destaining, leaving a light blue background on the gel. This makes photography and quantification of the proteins in the gel difficult and limits the sensitivity of the method.

We rediscovered a paper published in 1971 where Fairbanks et al. (1) proposed the use of three staining solutions, each containing $10 \%$ acetic acid and progressively lower concentrations 